ELECTROMAGNETICS LABORATORY

SCIENTIFIC REPORT NO. 86-8

AUGUST 1986

A SIMPLE CIRCULAR-POLARIZED ANTENNA: CIRCULAR WAVEGUIDE HORN COATED WITH LOSSY MAGNETIC MATERIAL

C. S. Lee

S. W. Lee

D. W. Justice

Supported by

Grant NAG3 - 475

NASA-Lewis Research Center

Cleveland, Ohio 44135

(NASA-CR-1770 2 ) A SIMELE

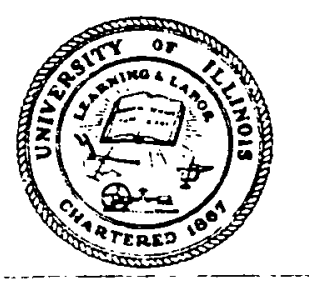

CIRCUIAR-POLAFIZED ANTENNA:: CIFCULAR

HAVEGUIDE HORN COATED WITH LOSSY MAGNETIC

MATERIAL (Illinois Univ., Urbana-Champaign.), Unclas

$32 \mathrm{p} \quad$ CSCL 20N G3/32 $\div 3552$

ELECTROMGGNETICS LABCRATGRY

DEPARTMENT OF ELECTRICAL AND COMPLTEK ENCINEERING

ENGINEERING EXPERTMENT STATION

UNIVERSITY OF ILLINOIS AT URBANA-CHAMPAIGN

URBANA, ILLINOIS 61801 
Electromagnetics Laboratory Report No. 86-8

\section{A SIMPLE CIRCULAR-POLARIZED ANTENNA: CIRCULAR WAVEGUIDE HORN COATED WITH LOSSY MAGNETIC MATERIAL}

by

C. S. Lee

S. W. Lee

D. W. Justice

Sclentific Report

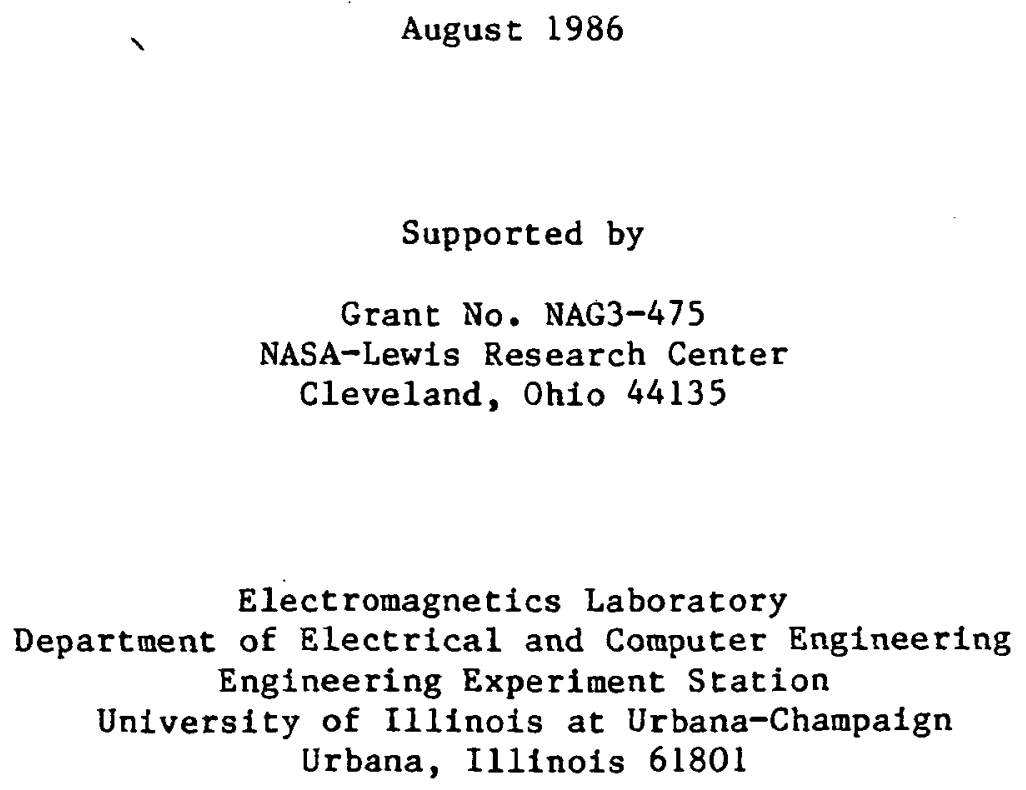


Abstract

A circular waveguide horn coated with a lossy material in its interior wall can be used as an alternative to a corrugated waveguide for radiating a circularly polarized (CP) fleld. To achieve good CP radiation, the diameter of the structure must be larger than the free-space wavelength, and the coating material must be sufficiently lossy and magnetic. This device is cheaper and lighter in weight than the corrugated one. 
TABLE OF CONTENTS

Page

I. INTRODUCTION . . . . . . . . . . . . . . . . . . 1

II. BOUNDARY CONDITIONS FOR THE BALANCED HYBRID MODE. . . . . . . . . 2

III. NUMERICAL RESULTS . . . . . . . . . . . . . . . . 7

IV. EXPERIMENT . . . . . . . . . . . . . . . . . . . 21

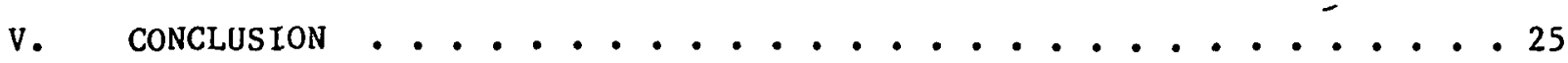


LIST OF FIGURES

Figure

Page

1. A coated circular guide. . . . . . . . . . . . . . 3

2. Radial wave number of the $\mathrm{HE}_{1 \mathrm{l}}$ mode as a function of the coating thickness $\left(\varepsilon_{2}=20, \mu_{2}=2.5 \exp \left(-\mathrm{j} \phi_{\mathrm{m}}\right), \phi_{\mathrm{m}}=45^{\circ}\right.$,

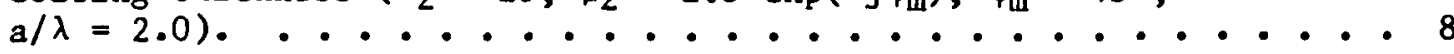

3. (a) Magnitudes of the tangential fields at the interface relative to those at the center of the waveguide, and

(b) attenuation constants of the $\mathrm{HE}_{11}$ mode in the lossy coated guide as a function of the inner radius a $\left(\varepsilon_{2}=20\right.$, $\left.\mu_{2}=2.5 \exp \left(-j \phi_{\mathrm{m}}\right), \phi_{\mathrm{m}}=45^{\circ}, \tau / \lambda=0.10, a_{0} / \lambda=2.0\right) . \ldots . .$. . 9

4. Magnitudes of the tangential fields of the $\mathrm{HE}_{11}$ mode as a function of the dielectric constant of the coating material $\left(\mu_{2}=2.5 \exp \left(-j \phi_{\mathrm{m}}\right), \phi_{\mathrm{m}}=45^{\circ}, a / \lambda=2.0, \tau / a=0.05\right) . . . .11$

5. Magnitudes of the tangential fields as a function of the magnitude of the relative magnetic permeability of the coating material $\left(\varepsilon_{2}=20, \mu_{2}=\left|\mu_{2}\right| \exp \left(-\mathrm{j} \phi_{\mathrm{m}}\right), \phi_{\mathrm{m}}=45^{\circ}\right.$, $a / \lambda=2.0, \tau / a=0.05) . . . . . . . . . . . . . . . . . .12$

6. Magnitudes of the tangential fields as a function of the magnitude of the dielectric constant which is the same as the relative magnetic permeability $\left(\varepsilon_{2}=\left|\varepsilon_{2}\right| \exp \left(-j \phi_{e}\right)\right.$, $\left.\phi_{e}=45^{\circ}, \mu_{2}=\varepsilon_{2}, a / \lambda=2.0, \tau / a=0.05\right) . \ldots . . . . . . . .13$

7. Phase angles of the tangential fields as a function of the magnitude of the dielectric constant which is the same as the relative magnetic permeability $\left(\varepsilon_{2}=\left|\varepsilon_{2}\right| \exp \left(-j \phi_{\mathrm{e}}\right)\right.$, $\left.\phi_{e}=45^{\circ}, \mu_{2}=\varepsilon_{2}, a / \lambda=2.0, \tau / a=0.05\right) . . . . . . . .14$

8. Radial wave numbers of the $\mathrm{HE}_{11}$ and $\mathrm{EH}_{11}$ modes as a function of the coating thickness $\left(\varepsilon_{2}=20, \mu_{2}=2.5 \exp \left(-j \phi_{m}\right)\right.$, $\left.\phi_{\mathrm{m}}=45^{\circ}, \mu_{2}=\varepsilon_{2}, a / \lambda=2.0, \tau / \mathrm{a}=0.05\right) . . . . . . . . . . .15$

9. Magnitudes of the tangential fields of the $\mathrm{HE}_{11}$ and $\mathrm{EH}_{11}$ modes as a function of the coating thickness $\left(\varepsilon_{2}=20\right.$, $\left.\mu_{2}=2.5 \exp \left(-j \phi_{m}\right), \phi_{m}=45^{\circ}, \mu_{2}=\varepsilon_{2}, a / \lambda=2.0, \tau / a=0.05\right) . . .16$

10. Attenuation constants of the $H_{11}$ and $E_{11}$ modes as a function of the coating thickness $\left(\varepsilon_{2}=20, \mu_{2}=2.5 \exp \left(-\mathrm{j} \phi_{\mathrm{m}}\right)\right.$, $\left.\phi_{\mathrm{m}}=45^{\circ}, \mu_{2}=\varepsilon_{2}, \mathrm{a} / \lambda=2.0, \tau / \mathrm{a}=0.05\right) . . . . . . . . . . .17$

11. Radial wave numbers of the $\mathrm{HE}_{11}$ and $\mathrm{EH}_{11}$ modes as a function of the coating thickness $\left(\varepsilon_{2}=20, \mu_{2}=2.5 \exp \left(-j \phi_{\mathrm{m}}\right)\right.$, $\left.\phi_{\mathrm{m}}=60^{\circ}, \mu_{2}=\varepsilon_{2}, \mathrm{a} / \lambda=2.0, \tau / \mathrm{a}=0.05\right) . . . . . . . . .19$ 
12. Magnitudes of the tangential fields as a function of the magnetic loss tangent of the coating material $\left(\varepsilon_{2}=20\right.$, $\left.\mu_{2}=2.5, a / \lambda=2.0, \tau / a=0.05\right) . . . . . . . . . . . . .20$

13. A horn coated with a lossy magnetic material. . . . . . . . . 22

14. Radiation patterns of the uncoated guide in Figure 13

$\left(\mathrm{a} / \lambda=2.02, \theta_{0}=8.4^{\circ}\right) . . . . . . . . . . . . . . .23$

15. Radiation patterns of the coated guide in Figure 13

$\left(\mathrm{a} / \lambda=2.02, \theta_{0}=8.4^{\circ}, \tau=3.18 \mathrm{~cm}, \varepsilon_{2}=24-\mathrm{j0} 0.48\right.$,

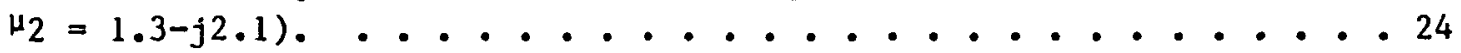




\section{INTRODUCTION}

Circularly polarized (CP) waves are important in many applications, such as radar systems, Ionospheric studies and radio astronomy. A good CP radiation can be produced by using an antenna with similar $\mathrm{E}-$ and $\mathrm{H}-\mathrm{plane}$ radiation patterns [1]. One of the first radiators having such a characteristic was the dual mode horn proposed by Potter in 1963 [2]. The Potter horn is simple, but has a narrow bandwidth and is difficult to control. A larger bandwidth can be achieved by using dielectric horns [3]-[5]. The most popular CP radiator is the corrugated horn, because of its excellent axial ratio and wide bandwidth [1], $[6]-[8]$. However, corrugated horns are expensive to manufacture and are heavy. In this paper, we w111 suggest an alternative: a regular circular waveglide horn coated with a lossy magnetic material [9], [10]. It is shown theoretically and experimentally that such a circular waveguide (approximately) satisfies the boundary condition for the "balanced hybrid" mode, and they have the same E- and H-plane radiation patterns.

The organization of this paper is as follows. In Section II, the condition for the identical E- and H-plane radiation patterns of a circular waveguide is derived. It is shown that such a condition can be approximately satisfied by coating the waveguide with a proper lossy magnetic material. In Section III, numerical results are given to verify the condition. In Section IV, experimental data of the radiation patterns of a coated circular horn are presented and compared with theoretical values. 
II. BOUNDARY CONDITIONS FOR THE BALANCED HYBRID MODE

Figure 1 shows a circular guide coated with a material of magnetic permeability $\mu_{2} \mu_{0}$ and dielectric permittivity $\varepsilon_{2} \varepsilon_{0}$, where $\mu_{0}$ and $\varepsilon_{0}$ are those of free space. The inner part of the cyllnder is assumed to be filled with a medium of $\mu_{1} \mu_{0}$ and $\varepsilon_{1} \varepsilon_{0}$. Here $\mu_{2}, \varepsilon_{2}, \mu_{1}$ and $\varepsilon_{1}$ are in general complex. The modal fields in such a guide were studied in detall [10]. Apart from a common factor

$$
\exp \left[j\left(\omega t-k_{z} z\right)\right]
$$

the tangential field components of a normal mode are described by the following expressions:

$$
\begin{aligned}
& E_{\phi}^{I}=j\left[\left\{A_{z} m /\left(k_{1} k_{\rho 1} \rho\right)\right\} F_{1}(\rho)+B F_{1}^{\prime}(\rho)\right] e^{j m \phi} \\
& E_{\phi}^{I I}=j\left[\left\{\mathrm{Ck}_{z} m /\left(k_{2} k_{\rho 2} \rho\right)\right\} F_{3}(\rho)+D F_{4}^{\prime}(\rho)\right] e^{j m \phi} \\
& E_{z}^{I}=j\left(A k_{\rho 1} / k_{1}\right) F_{1}(\rho) e^{j m \phi} \\
& E_{z}^{I I}=j\left(C k_{\rho 2} / k_{2}\right) F_{3}(\rho) e^{j m \phi} \\
& H_{\phi}^{I}=-Y_{1}\left[F_{1}^{\prime}(\rho)+\left\{B k_{z} m /\left(k_{1} k_{\rho 1} \rho\right)\right\} F_{1}(\rho)\right] e^{j m \phi} \\
& H_{\phi}^{I I}=-Y_{2}\left(C F_{3}^{\prime}(\rho)+\left\{D k_{z} m /\left(k_{2} k_{\rho 2} \rho\right)\right\} F_{4}(\rho)\right] e^{j m \phi} \\
& H_{z}^{I}=-j Y_{1}\left(B k_{\rho 1} / k_{1}\right) F_{1}(\rho) e^{j m \phi} \\
& H_{z}^{I I}=-j Y_{2}\left(D k_{\rho 2} / k_{2}\right) F_{4}(\rho) e^{j m \phi}
\end{aligned}
$$



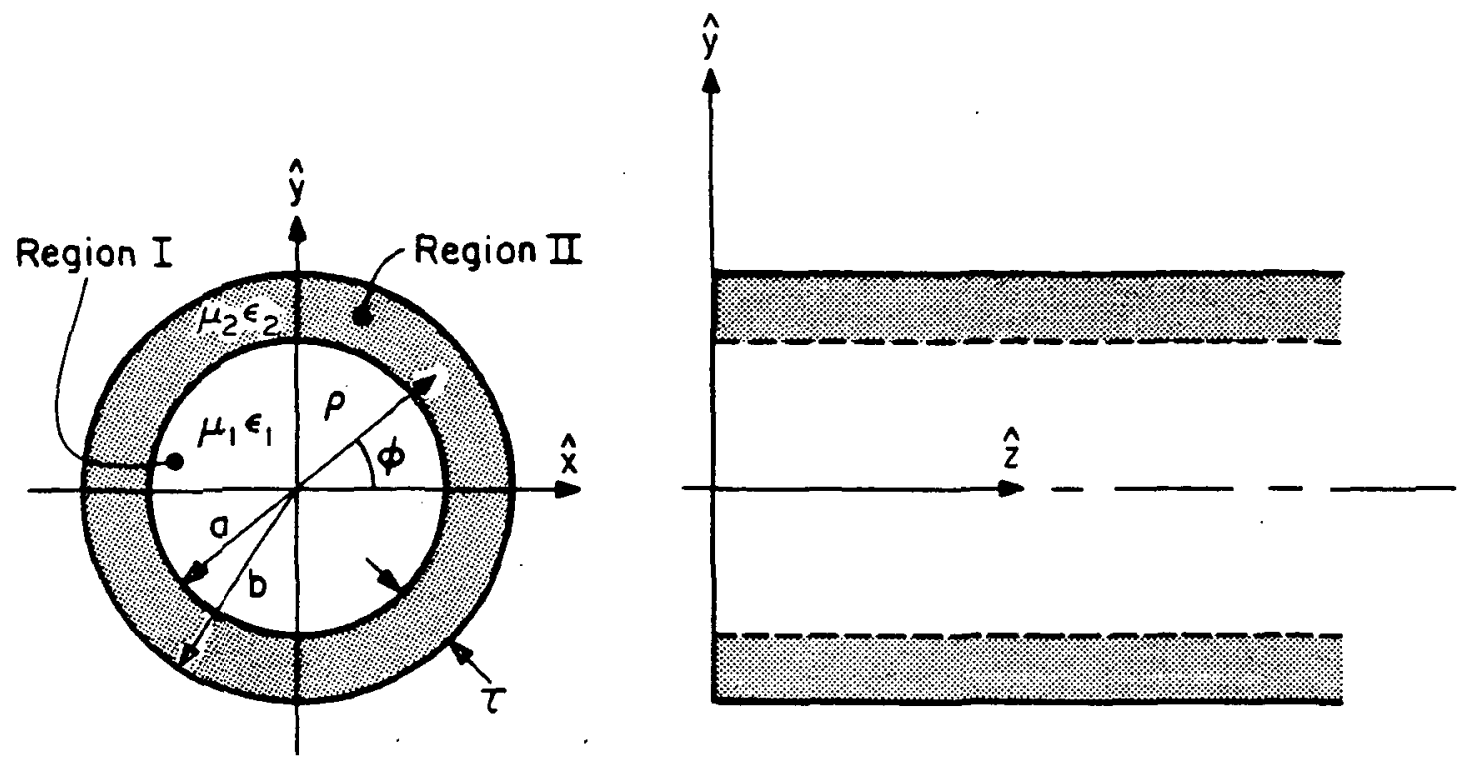

Figure 1. A coated circular guide. 
where

$$
\begin{aligned}
& k_{\rho 1}^{2}+k_{z}^{2}=\varepsilon_{1} \mu_{1} k_{0}^{2} \equiv k_{1}^{2}, Y_{1}=\left(\varepsilon_{1} / \mu_{1}\right)^{1 / 2} \\
& k_{\rho 2}^{2}+k_{z}^{2}=\varepsilon_{2} \mu_{2} k_{0}^{2} \equiv k_{2}^{2}, Y_{2}=\left(\varepsilon_{2} / \mu_{2}\right)^{1 / 2} \\
& F_{1}(\rho)=J_{m}\left(k_{\rho 1} \rho\right), F_{1}^{\prime}(\rho)=J_{m}^{\prime}\left(k_{\rho 1} \rho\right) \\
& F_{3}(\rho)=J_{m}\left(k_{\rho 2} \rho\right) N_{m}\left(k_{\rho 2} b\right)-N_{m}\left(k_{\rho 2} \rho\right) J_{m}\left(k_{\rho 2} b\right) \\
& F_{3}^{\prime}(\rho)=J_{m}^{\prime}\left(k_{\rho 2} \rho\right) N_{m}\left(k_{\rho 2} b\right)-N_{m}^{\prime}\left(k_{\rho 2} b\right) J_{m}\left(k_{\rho 2} b\right) \\
& F_{4}(\rho)=J_{m}\left(k_{\rho 2} \rho\right) N_{m}^{\prime}\left(k_{\rho 2} b\right)=N_{m}\left(k_{\rho 2} \rho\right) J_{m}^{\prime}\left(k_{\rho 2} b\right) \\
& F_{4}^{\prime}(\rho)=J_{m}^{\prime}\left(k_{\rho 2} \rho\right) N_{m}^{\prime}\left(k_{\rho 2} b\right)-N_{m}^{\prime}\left(k_{\rho 2} \rho\right) J_{m}^{\prime}\left(k_{\rho 2} b\right)
\end{aligned}
$$

Here superscripts I and II Indicate Regions I and II (FIgure 1), respectively. For a nontrivial solution of constants (A, B, C, D), the propagation constant $\mathrm{k}_{z}$ satisfies the characteristic equation

$$
\left|\begin{array}{cccc}
k_{\rho 1}^{2} F_{1}(a) / \varepsilon_{1} & 0 & k_{\rho 2}^{2} F_{3}(a) / \varepsilon_{2} & 0 \\
0 & k_{\rho 1}^{2} F_{1}(a) / \mu_{1} & 0 & k_{\rho 2}^{2} F_{4}(a) / \mu_{2} \\
k_{\rho 1} F_{1}^{\prime}(a) & \frac{k_{z}^{m} F_{1}(a)}{\omega \mu_{1}^{a}} & k_{\rho 2} F_{3}^{\prime}(a) & \frac{k_{z}^{m}}{\omega \mu_{2} F_{4}(a)} \\
\frac{k_{z}^{m}}{\omega \varepsilon_{1}^{a}} & k_{\rho 1} F_{1}^{\prime}(a) & \frac{k_{z}^{m}}{\omega \varepsilon_{2} F_{3}(a)} & k_{\rho 2} F_{4}^{\prime}(a)
\end{array}\right|=0
$$


For a guide dimension $(a, b)$ and material $\left(\varepsilon_{1}, \mu_{1}, \varepsilon_{2}, \mu_{2}\right)$, we can determine a set of multiple solutions for $k_{z}$, each of which describes the propagation constant of a normal mode. Now, for a particular combination of $(a, b)$ and $\left(\varepsilon_{1}, \mu_{1}, \varepsilon_{2}, \mu_{2}\right)$, an additional boundary condition at the interface $\rho=a$ may be satisfied for a special mode, namely,

$$
\rho \times\left[Y_{0} \vec{E} \pm j \vec{H}\right]=0 \text {, at } \rho=a
$$

This mode is called a "balanced hybrid mode." It is known [1] that the radiation field of this mode with a proper feed is circularly polarized.

If the balanced hybrid mode condition ( 3 ) is enforced on the normal mode expressions in (2), we obtain an additional characteristic equation, namely,

$$
B F_{1}(a) \frac{\mu_{2} k_{\rho 1}}{\mu_{1} k_{\rho 2}}\left[\frac{F_{4}^{\prime}(a)}{F_{4}(a)}-\frac{F_{3}^{\prime}(a)}{F_{3}(a)} \frac{\varepsilon_{2} \mu_{1}}{\varepsilon_{1} \mu_{2}}\right]=0
$$

At the high-frequency limit, Eq. (5) becomes

$$
j B F_{1}(a) \frac{\mu_{2} k_{\rho 1} a \operatorname{coth}\left(\tilde{k}_{\rho 2} \tau\right)}{\mu_{1} \sqrt{\varepsilon_{2} \mu_{2}-\varepsilon_{1} \mu_{1}} k_{0} a}\left[\tanh ^{2}\left(\tilde{k}_{\rho 2} \tau\right)-\frac{\varepsilon_{2} \mu_{1}}{\varepsilon_{1} \mu_{2}}\right] \approx 0
$$

where

$$
\dot{\mathrm{k}}_{\rho 2}=\mathbf{j} \tilde{\mathrm{k}}_{\rho 2}, \tau \neq b-a
$$

The terms in the bracket vanish only when $\varepsilon_{2} \mu_{1} / \varepsilon_{1} \mu_{2}$ is real and less than unity. The dielectric horn utilizes this condition [5]. On the other hand, the above equation is also approximately satisfied when the coating material is very 
lossy. In this limit, the normal mode becomes an "inner mode," the fields of which are expelled from the lossy layer and decay exponentially into the lossy region [10]; the 1maginary part of $k_{\mathrm{p} 2}$ becomes very large; and Eq. (6) can be wel1-approximated by

$$
j B F_{1}(a) \frac{\mu_{2} k_{\rho 1} a}{\mu_{1} k_{0} a \sqrt{\varepsilon_{2} \mu_{2}-\varepsilon_{1} \mu_{1}}}\left[1-\frac{\varepsilon_{2} \mu_{1}}{\varepsilon_{1} \mu_{2}}\right] \approx 0
$$

This function is a monotonically decreasing function of frequency, assuming $B F_{1} k_{\rho l}$ a does not vary much with frequency. In fact, as w1ll be seen 1 the next section, $\mathrm{BF}_{1} \mathrm{k}_{\rho \mathrm{l}} \mathrm{a}$ is nearly constant at high frequencles when the coating material is very lossy. Thus at sufficiently high frequencies, the condition of Eq. (5) for the balanced hybrid mode can be easily met. In this case, the fields at the interface nearly vanish and the characteristic equation deduced in Eq. (3) is approximately given by

$$
\left[F_{1}^{\prime}(a) / F_{1}(a)\right]^{2}-\left(m / k_{\rho 1} a\right)^{2}=0
$$

The radial wave number in Region $I$ for the dominant $H E_{11}$ mode is given by $k_{\rho 1} a=$ 2.405, which is obtalned from the lowest zero of $\mathrm{J}_{0}$. The transverse fields of this mode are linearly polarized [10], [13]. It is interesting to note that when $\varepsilon_{2}=\mu_{2}$, Eq. (8) can be satisfied even if the flelds at the interface do not vanish. More discussion will be given in Section III.

The condition of $\mathrm{Eq}$. (5) can be also satisfied at high frequencies when $\varepsilon_{2} \mu_{1} / \varepsilon_{1} \mu_{2}$ is real and much smaller than unity [5]. On the other hand, the dielectric constant of the material in Region I for the lossy coated guide can be low to satisfy Eq. (5). A convenient cholce of the material would be air. 


\section{NUMERICAL RESULTS}

The medium in Region I is assumed to be afr, and only the case of the waveguide coated with a lossy material is considered. It has been shown that most of the low-order modes become inner modes, the modal fields of which are mostly confined within the air region as a/ $\lambda$ increases [10]. In this paper, we concentrate on the $\mathrm{HE}_{11}$ mode, which is most important in the CP-antenna applications. The propagation constants of the normal mode are obtained numerically from the characteristic equation in Eq. (3) by using Muller's method.

Figure 2 shows the radial wave number (RWN) In Region I of the $\mathrm{HE}_{11}$ mode in a waveguide coated with a lossy magnetic material as a function of the coating thickness. Here we plotted the RWN instead of the propagation constant because the modal behavior can be more easily understood from the RWN than the propagation constant. Note that the RWN becomes nearly independent as the coating thickness increases. Th1s implies that the modal fields do not penetrate into the lossy layer farther than the skin depth of the flelds. We note that the real value of the radial wave number of the $\mathrm{HE}_{11}$ mode in the magnetic-coated guide is close to $2.40 / a$. This trend indicates that this normal mode is the dominant mode and both the tangential electric and magnetic fields are small at the interface. As a/ $\lambda$ increases, the tangential components of the electric and magnetic fields at the interface decrease monotonically (Figure 3a). In other words, the fields are expelled from the lossy layer at a large value of a/ $\lambda$, and the attenuation decreases very rapidly as frequency increases (Figure $3 b$ ). Note that the exact solutions agree well with the asymptotic solutions by Marcatili and Schmeltzer [13] where small fields in the lossy layer are assumed. Now it is clear that we will obtain better $C P$ radiation with a waveguide with a larger value of $a / \lambda$. 


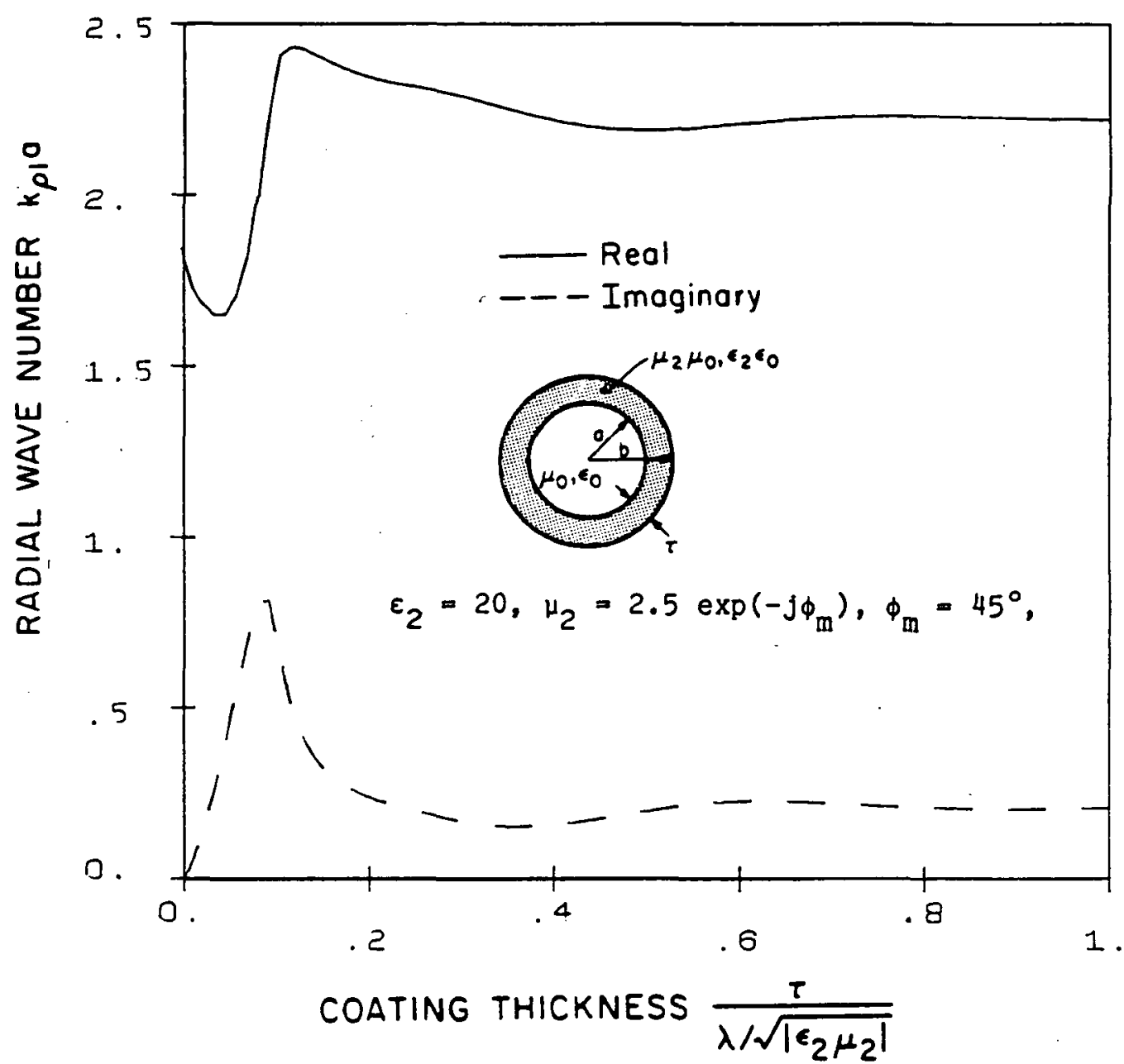

Figure 2. Radial wave number of the $\mathrm{HE}_{11}$ mode as a function of the coating thickness $\left(\varepsilon_{2}=20, \mu_{2}=2.5 \exp \left(-j \phi_{m}\right), \phi_{m}=45^{\circ}, a / \lambda=2.0\right)$. 


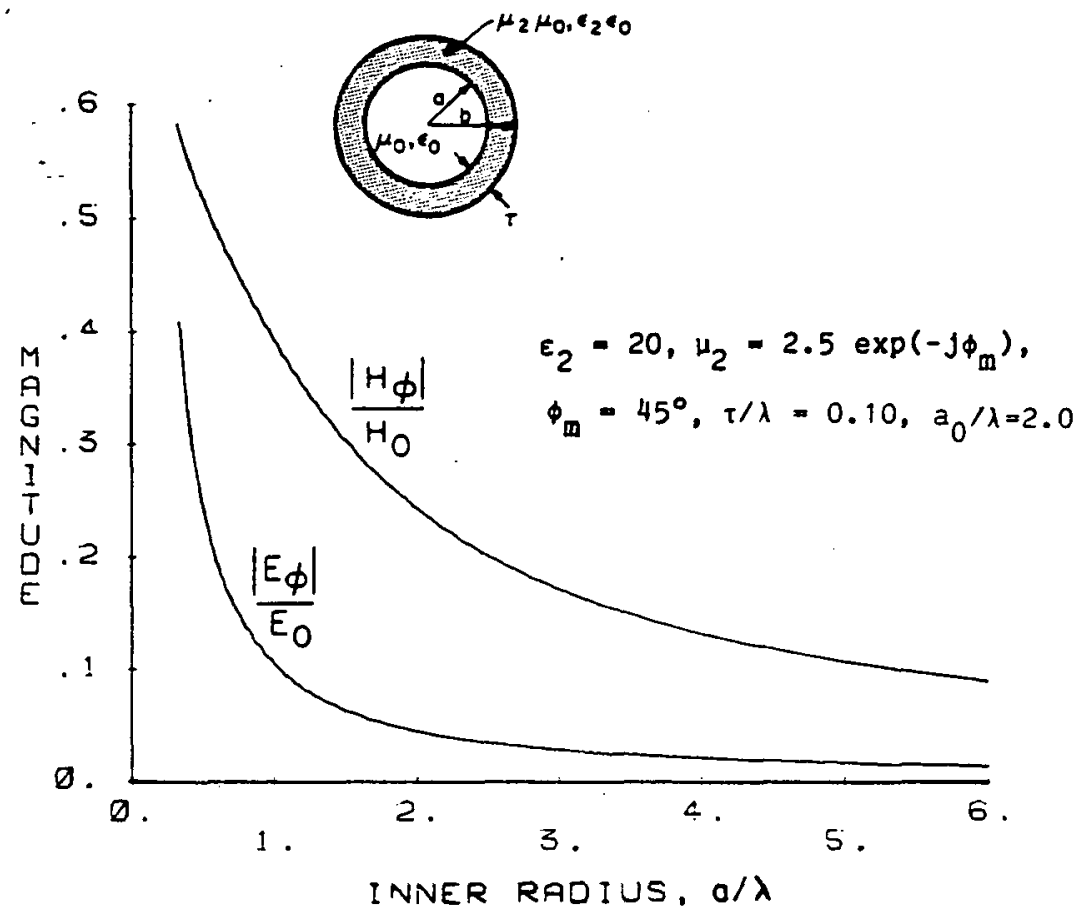

(a)

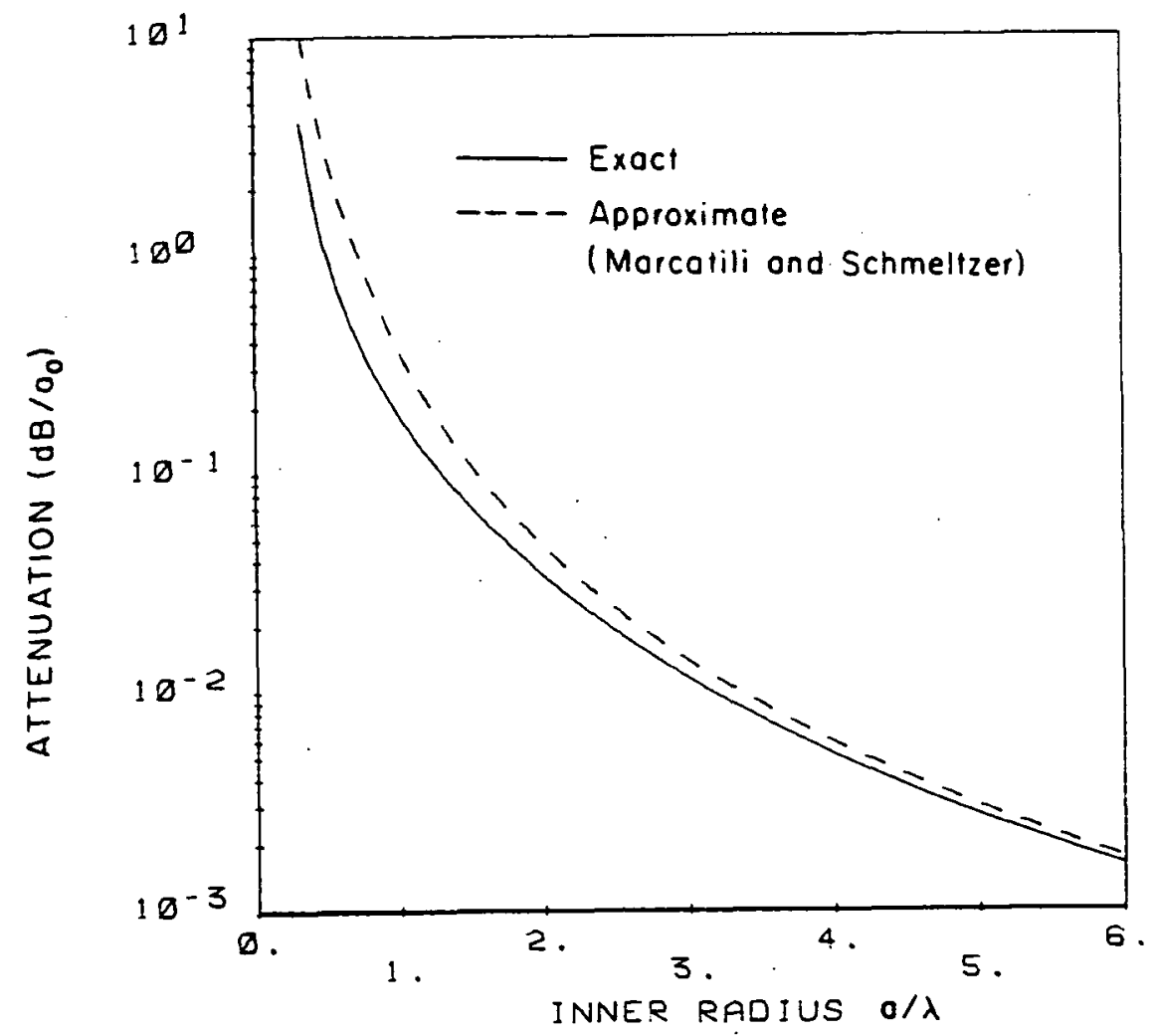

(b)

Figure 3. (a) Magnitudes of the tangential fields at the interface relative to those at the center of the waveguide, and (b) attenuation constants of the $\mathrm{HE}_{11}$ mode in the lossy coated guide as a function of the inner radius a $\left(\varepsilon_{2}=20, \mu_{2}=2.5 \exp \left(-j \phi_{m}\right), \phi_{m}=45^{\circ}, \tau / \lambda=0.10\right.$, $a_{0} / \lambda=2.0$ ). 
The tangential magnetic field $\mathrm{H}$ at the interface can be reduced when the dielectric constant is lowered, but the tangential electric field E increases in this case (F1gure 4). On the other hand, the $\mathrm{H}$ fleld decreases and the $E$ field increases as the magnitude of the magnetic permeability increases (Figure 5). The Ideal material has the same dielectric constant as the relative magnetic permeability (Figures 6 and 7). In the waveguide coated with this ideal material, those two tangentlal fields are usually small but fintte. But notice that those fields are equal not only in magnitude but also in phase, which is the requirement for a good balanced hybrid mode (see Section III).

The coating in the waveguide must be gradual for a proper transition of the $\mathrm{TE}_{11}$ mode in the uncoated section of the waveguide to the $\mathrm{HE}_{11}$ mode in the coated section. Figure 8 shows the RWNs of the $\mathrm{HE}_{11}$ and $\mathrm{EH}_{11}$ modes as a function of the coating thickness when the coating material is sufficiently lossy. The small imaginary part of the RWN of the $\mathrm{HE}_{11}$ mode indicates that the normal mode becomes the inner mode whose modal fields are confined within the air region and whose attenuation constant is small. On the other hand, the larger imaginary part of the RWN of the $\mathrm{EH}_{11}$ mode implies that the modal fields are shifted more to the surface of the waveguide and the flelds at the interface are larger than those of the $\mathrm{HE}_{11}$ mode (Figure 9). Consequently the attenuation of the $\mathrm{EH}_{11}$ mode is larger than that of the $\mathrm{HE}_{11}$ mode (F1gure 10). In general, higher-order modes have larger flelds at the interface than lower-order modes, and the mode conversion of the $\mathrm{HE}_{11}$ mode to the higher-order modes is not desirable for $\mathrm{CP}$ radiation. As shown in Figure 8, the RWNs (and the propagation constants) of those two modes become close to each other before they become two completely different modes as the coating thickness increases. The mode conversion of the $\mathrm{HE}_{11}$ to $\mathrm{EH}_{11}$ mode is more likely to occur near the thickness of the 


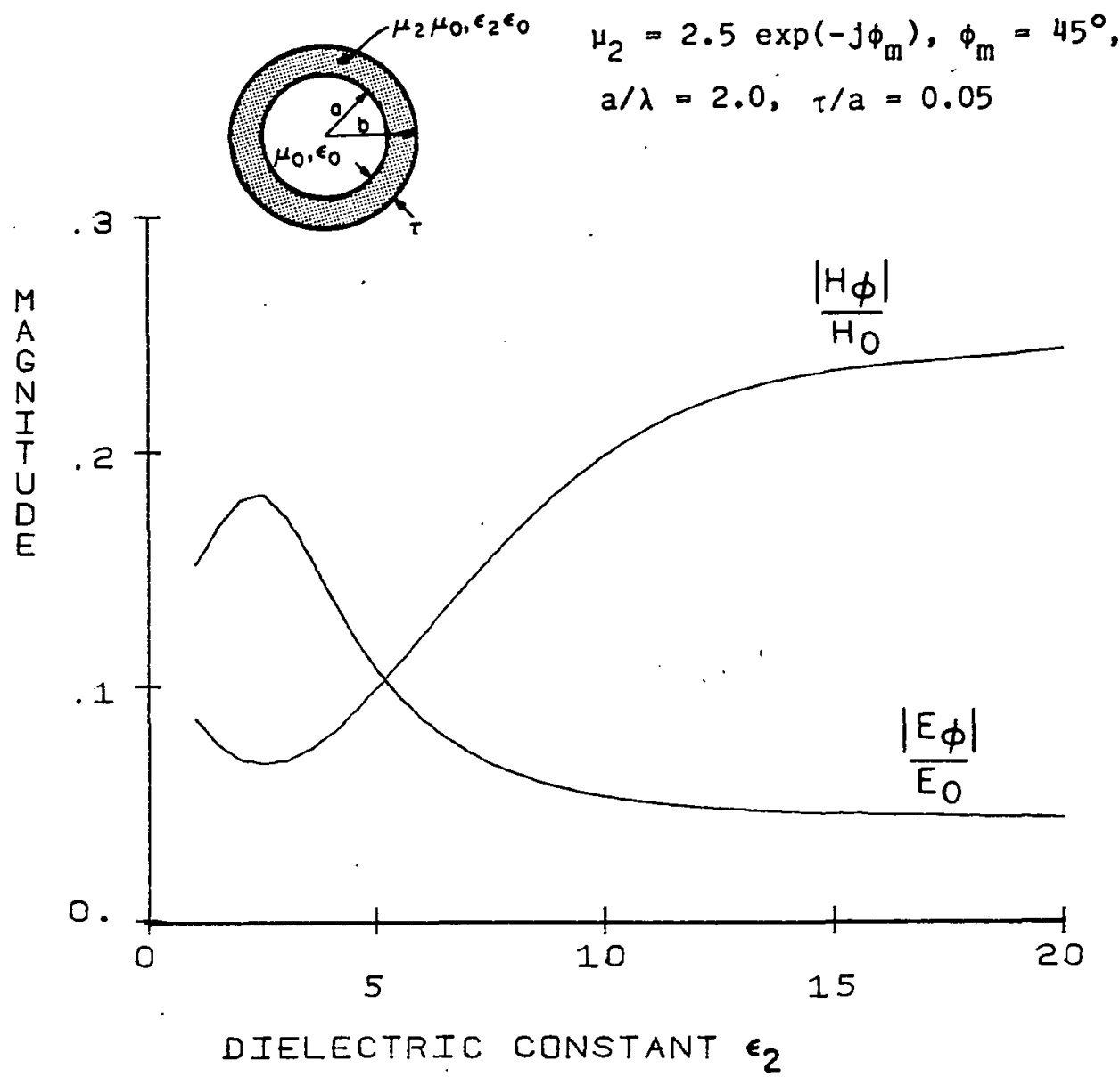

Figure 4. Magnitudes of the tangential fields of the HE 11 mode as a function of the dielectric constant of the coating material $\left(\mu_{2}=2.5\right.$ $\left.\exp \left(-j \phi_{\mathrm{m}}\right), \phi_{\mathrm{m}}=45^{\circ}, \mathrm{a} / \lambda=2.0, \tau / \mathrm{a}=0.05\right)$. 


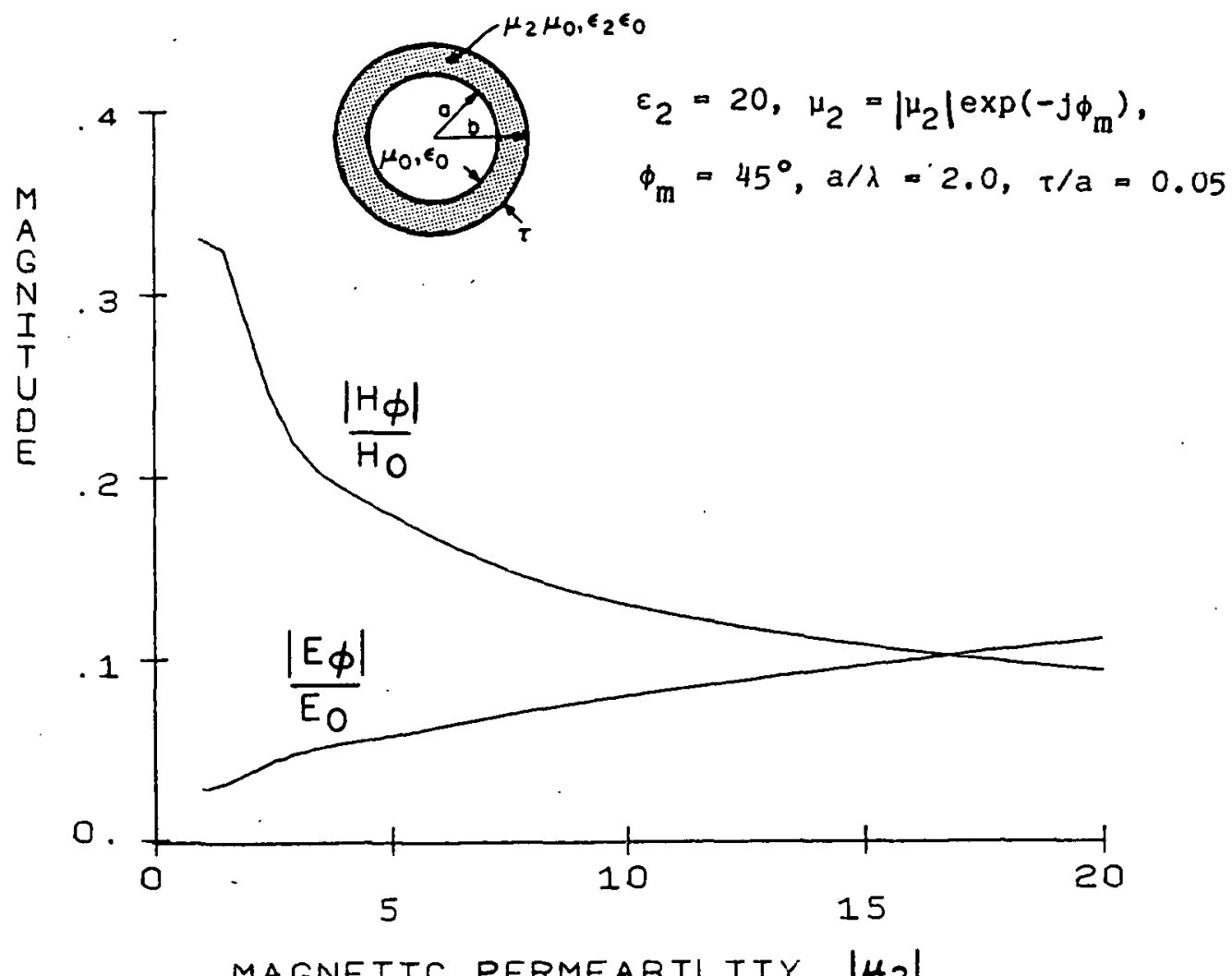

MAGNETIC PERMEABILITY $\left|\mu_{2}\right|$

Figure 5. Magnitudes of the tangential fields as a function of the magnitude of the relative magnetic permeability of the coating material $\left(\varepsilon_{2}=\right.$ 20, $\left.\mu_{2}=\left|\mu_{2}\right| \exp \left(-j \phi_{\mathrm{m}}\right), \phi_{\mathrm{m}}=45^{\circ}, \mathrm{a} / \lambda=2.0, \tau / \mathrm{a}=0.05\right)$. 


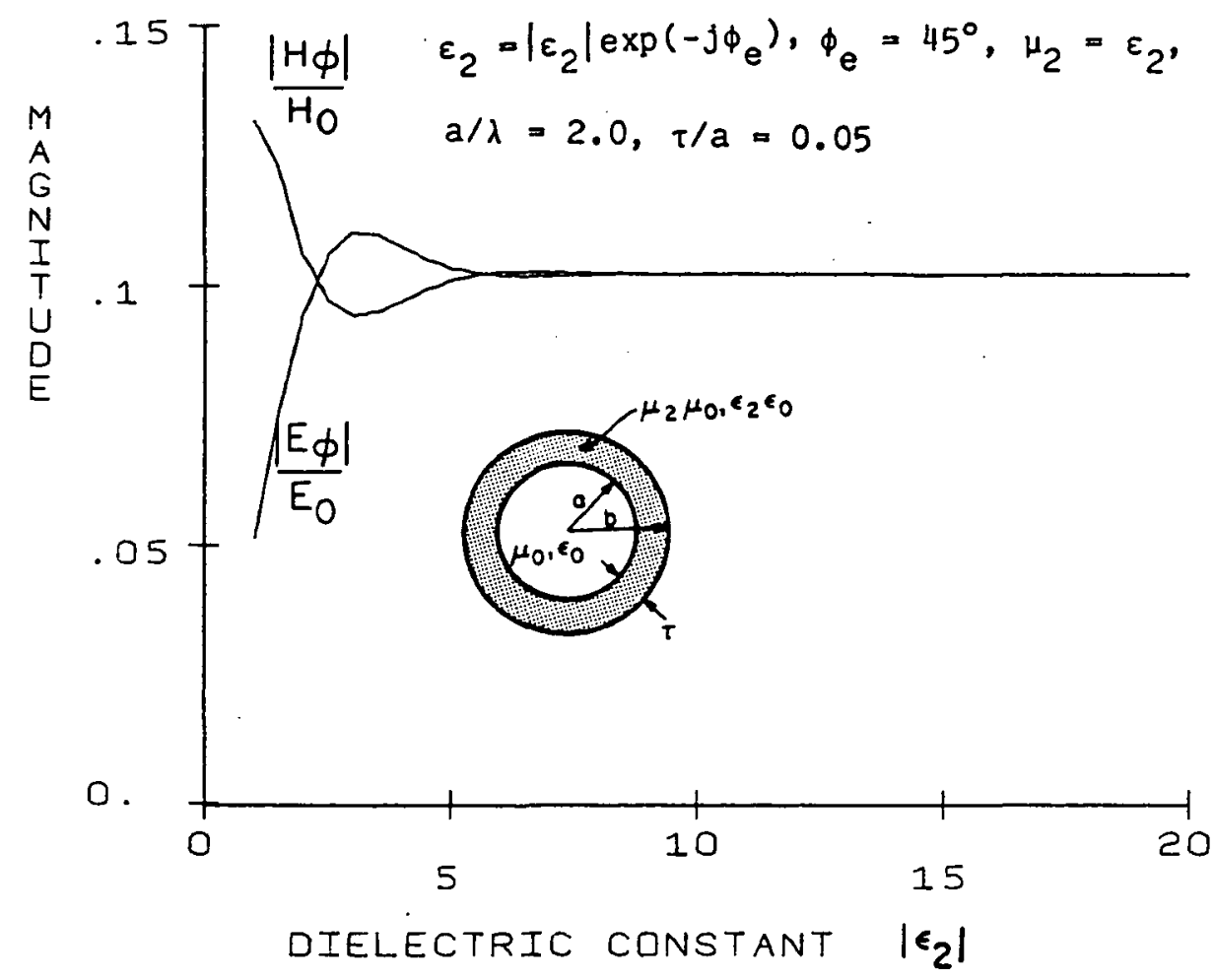

Figure 6. Magnitudes of the tangential fields as a function of the magnitude of the dielectric constant which is the same as the relative magnetic permeability $\left(\varepsilon_{2}=\left|\varepsilon_{2}\right| \exp \left(-j \phi_{e}\right), \phi_{e}=45^{\circ}, \mu_{2}=\varepsilon_{2}, a / \lambda=2.0\right.$, $\tau / a=0.05)$. 


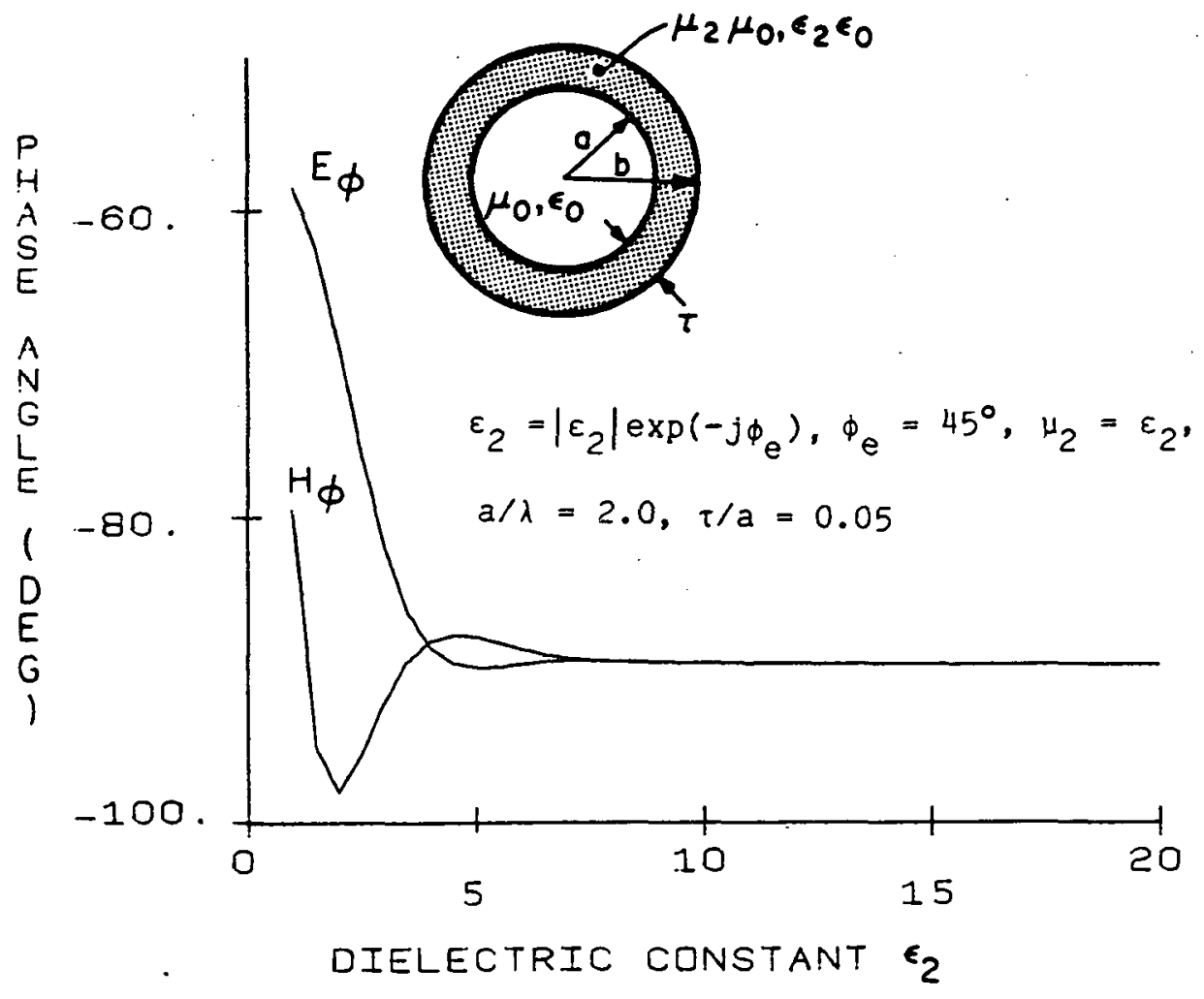

Figure 7. Phase angles of the tangential fields as a function of the magnitude of the dielectric constant which is the same as the relative magnetic permeability $\left(\varepsilon_{2}=\left|\varepsilon_{2}\right| \exp \left(-j \phi_{e}\right), \phi_{e}=45^{\circ}, \mu_{2}=\varepsilon_{2}, a / \lambda=2.0\right.$, $\tau / a=0.05)$. 


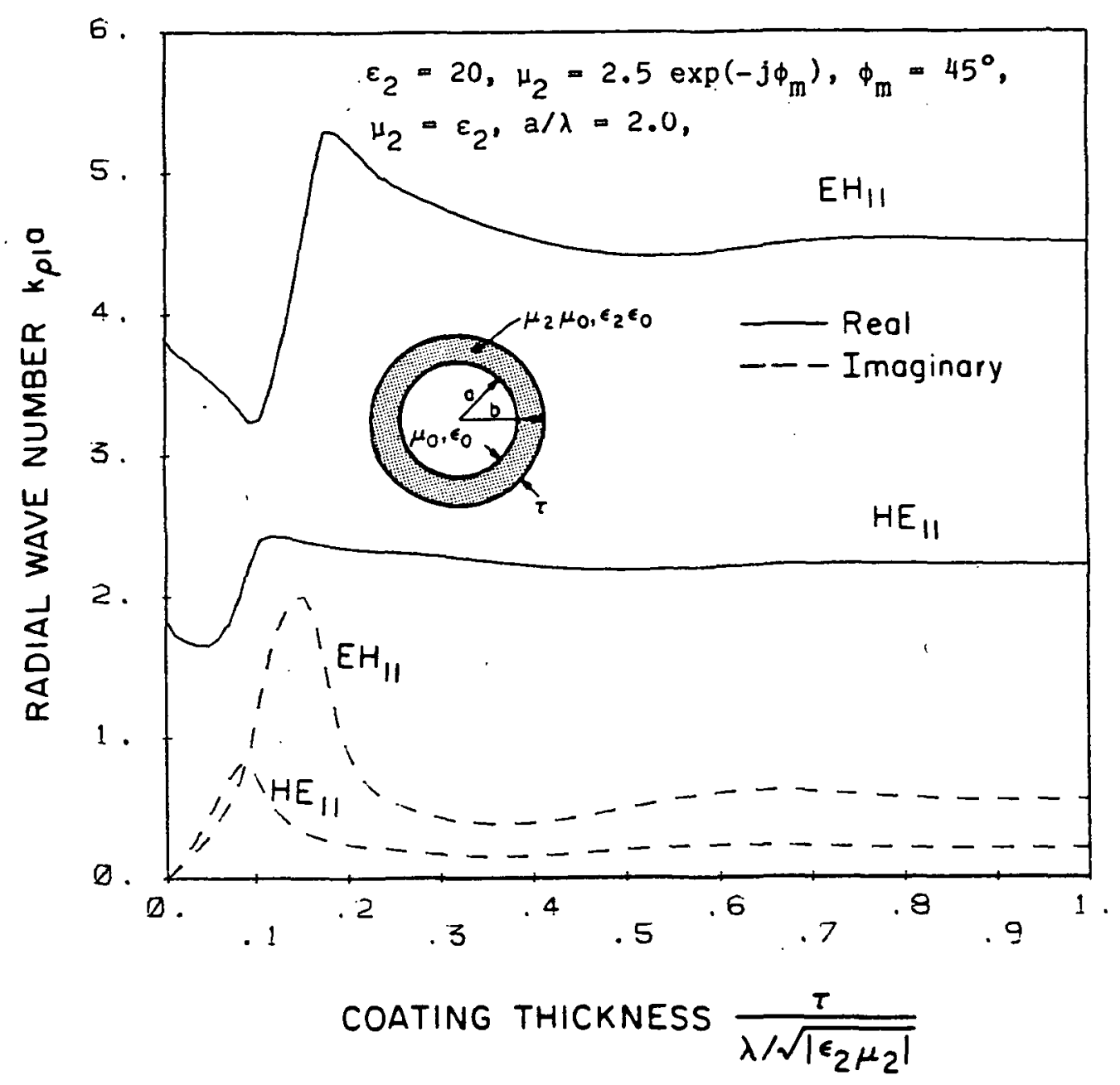

Figure 8. Radial wave numbers of the $\mathrm{HE}_{11}$ and $\mathrm{EH}_{11}$ modes as a function of the coating thickness $\left(\varepsilon_{2}=20, \mu_{2}=2.5 \exp \left(-\mathrm{j} \phi_{\mathrm{m}}\right), \phi_{\mathrm{m}}=45^{\circ}, \mu_{2}=\varepsilon_{2}\right.$, $a / \lambda=2.0, \tau / a=0.05)$. 


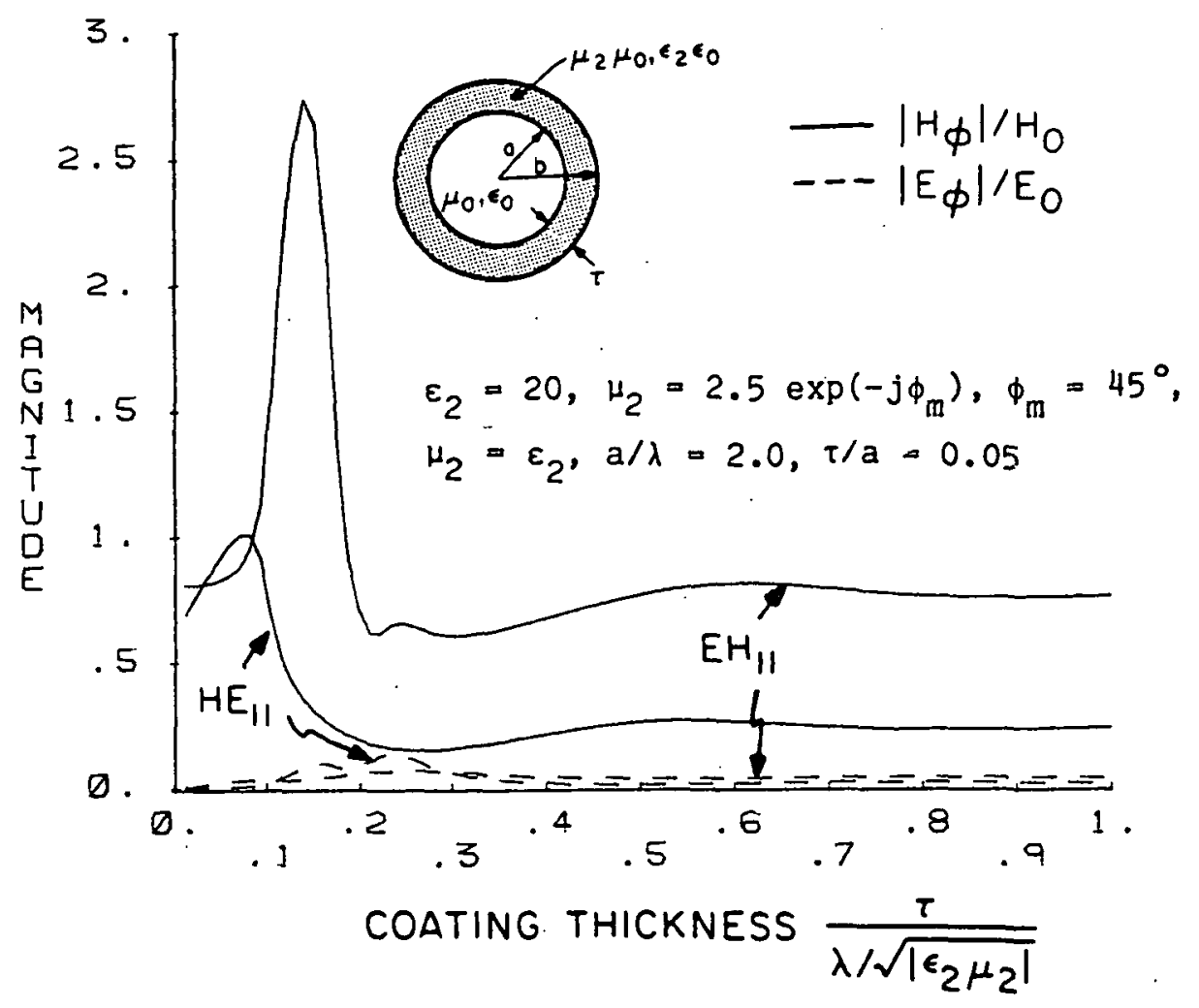

Figure 9. Magnitudes of the tangentlal fields of the $\mathrm{HE}_{11}$ and $\mathrm{EH}_{11}$ modes as a function of the coating thickness $\left(\varepsilon_{2}=20, \mu_{2}=2.5 \exp \left(-j \phi_{m}\right), \phi_{m}=\right.$ $\left.45^{\circ}, \mu_{2}=\varepsilon_{2}, a / \lambda=2.0, \tau / a=0.05\right)$. 


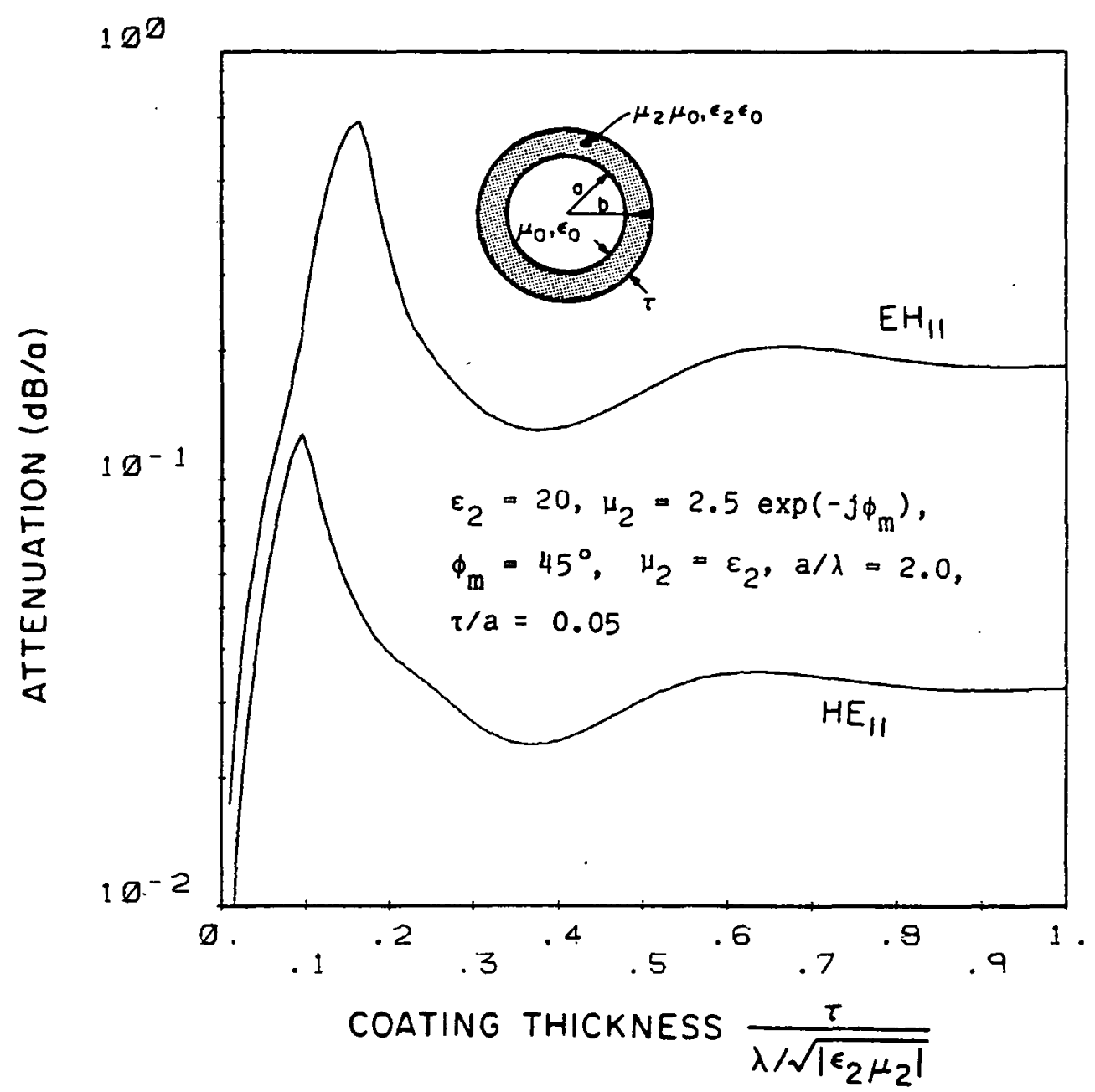

Figure 10. Attenuation constants of the $\mathrm{HE}_{11}$ and $\mathrm{EH}_{11}$ modes as a function of the coating thickness $\left(\varepsilon_{2}=20, \mu_{2}=2.5 \exp \left(-j \phi_{m}\right), \phi_{\mathrm{m}}=45^{\circ}, \mu_{2}=\right.$ $\varepsilon_{2}, a / \lambda=2.0, \tau / a=0.05$ ). 
coating layer where the RWNs come close to each other [14]. Thus the mode conversion may be a problem as the dominant $\mathrm{TE}_{11}$ mode in the uncoated section of the waveguide is transformed to the $\mathrm{HE}_{11}$ mode in the coated section. In fact, the $\mathrm{HE}_{11}$ mode becomes the surface mode if the magnet1c loss tangent of the coating material is small [10]. When a more lossy material is chosen for the coating, the separation of the RWNs of those two modes is larger (Figure 11) and the mode-conversion problem can be abated. Thus in practice the coating material must be not only magnetic but also sufficlently lossy. However increasing the magnetic loss tangent does not help in reducing the tangential fields at the interface (Figure 12). 


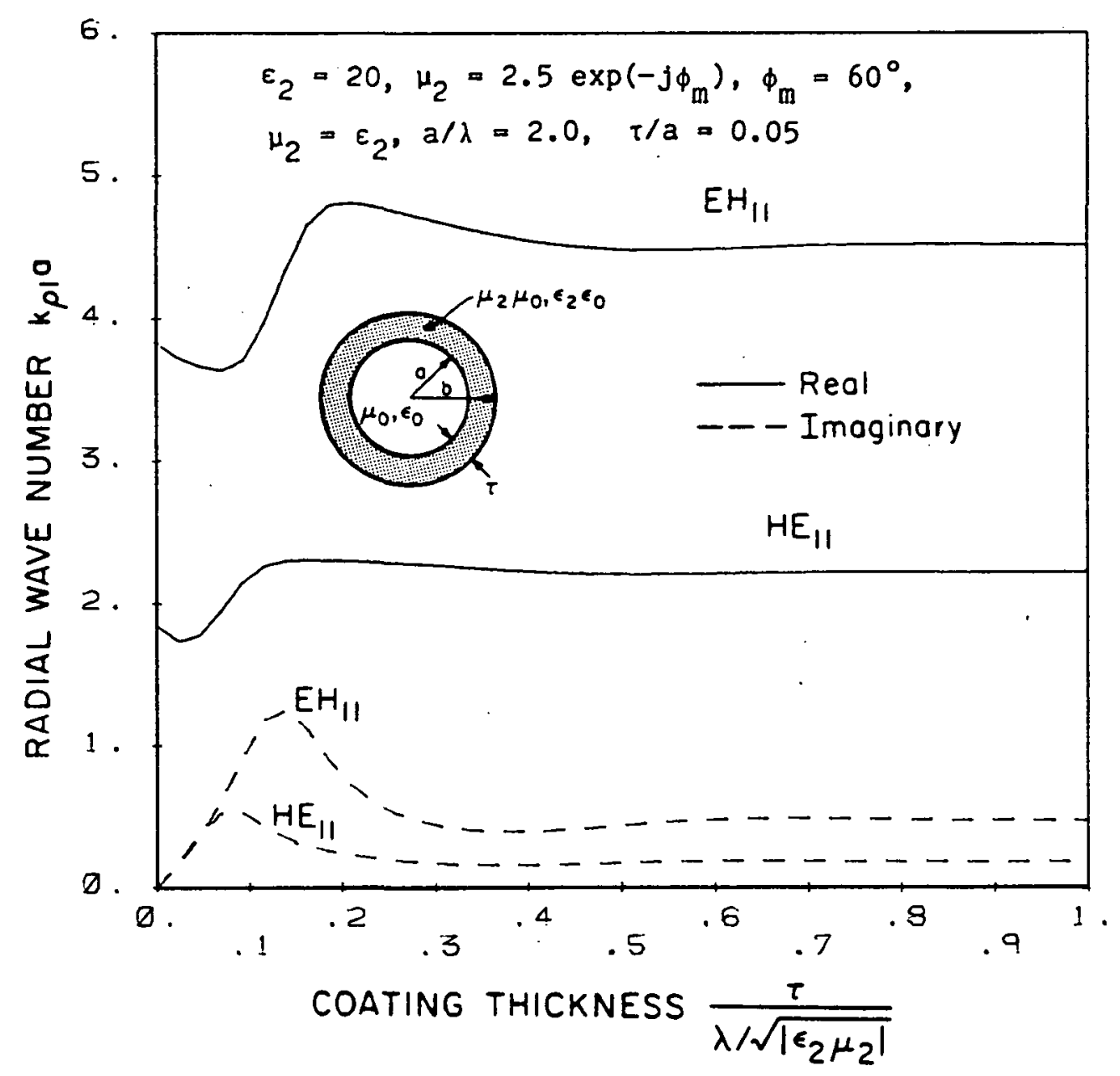

Figure 11. Radial wave numbers of the $\mathrm{HE}_{11}$ and $\mathrm{EH}_{11}$ modes as a function of the coating thickness $\left(\varepsilon_{2}=20, \mu_{2}=2.5 \exp \left(-j \phi_{\text {m }}\right), \phi_{\text {m }}=60^{\circ}, \mu_{2}=\varepsilon_{2}\right.$, $a / \lambda=2.0, \tau / a=0.05)$. 


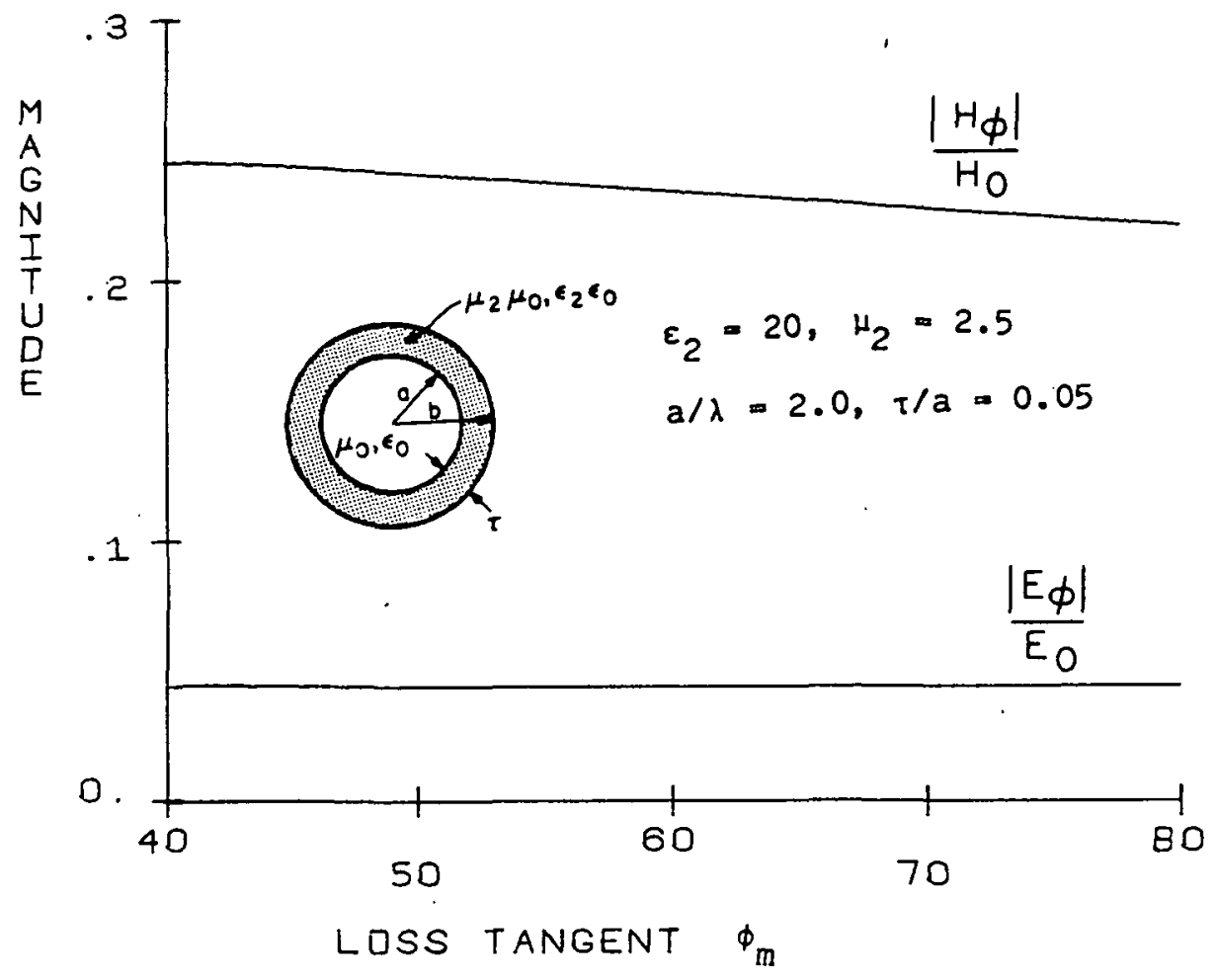

Figure 12. Magnitudes of the tangential fields as a function of the magnetic loss tangent of the coating material $\left(\varepsilon_{2}=20, \mu_{2}=2.5, a / \lambda=2.0\right.$, $\tau / a=0.05)$. 


\section{EXPERIMENT}

Figure 13 shows the coated horn for the radiation-pattern measurements. To reduce the mode conversion of the $\mathrm{HE}_{11}$ mode to the higher-order modes, almost the entire section of the horn is coated with a lossy magnetic material. For the purpose of comparison, the measured radiation patterns of an uncoated horn in the $\mathrm{E}$ and $\mathrm{H}$ planes are shown in Figures 14 and 15 . Those two radiation patterns become very similar when the waveguide is coated with a lossy magnetic material (Figure 14). These experimental data also agree well with the theoretical values, which have been obtained by a Kirchhoff-Huygen integration [3] over the confcal aperture of the horn, assuming both the tangential $\mathrm{E}$ and $\mathrm{H}$ fields vanish at the interface. We also note that the side-lobe level is reduced significantly after the horn is coated.

We observed that the level at the boresight was reduced by $10 \mathrm{~dB}$ after the coating was applied. Most of the attenuation is believed to occur at the region of the smaller cross-sectional area. When only a small section near the horn mouth is coated, the reduction of the power at the boresight is not significant, but the two radiation patterns in the $\mathrm{E}$ and $\mathrm{H}$ planes are not as similar as when the entire section of the horn is coated. This may be due to the higher-mode excitations because the mode conversion is more likely to occur when the transition of the coating is at the region of a larger cross section near the horn opening [14]. In a practical design, a power compromise between the power loss problem and the mode-conversion problem may be chosen. Special attention should be given in reducing the power loss without serious mode conversion of the $\mathrm{HE}_{11}$ mode to the higher-order modes. 

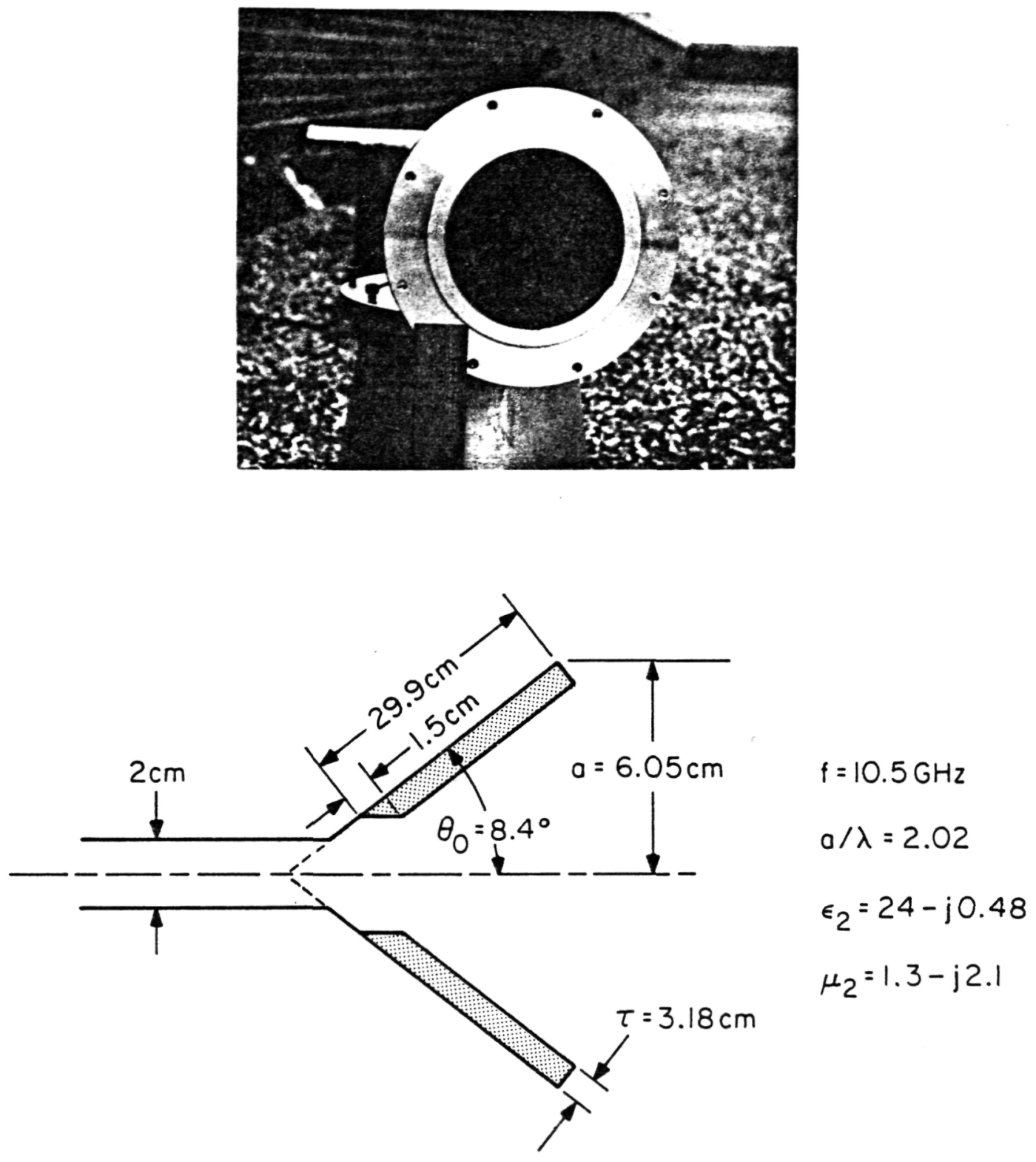

Figure 13. A horn coated with a lossy magnetic material. 


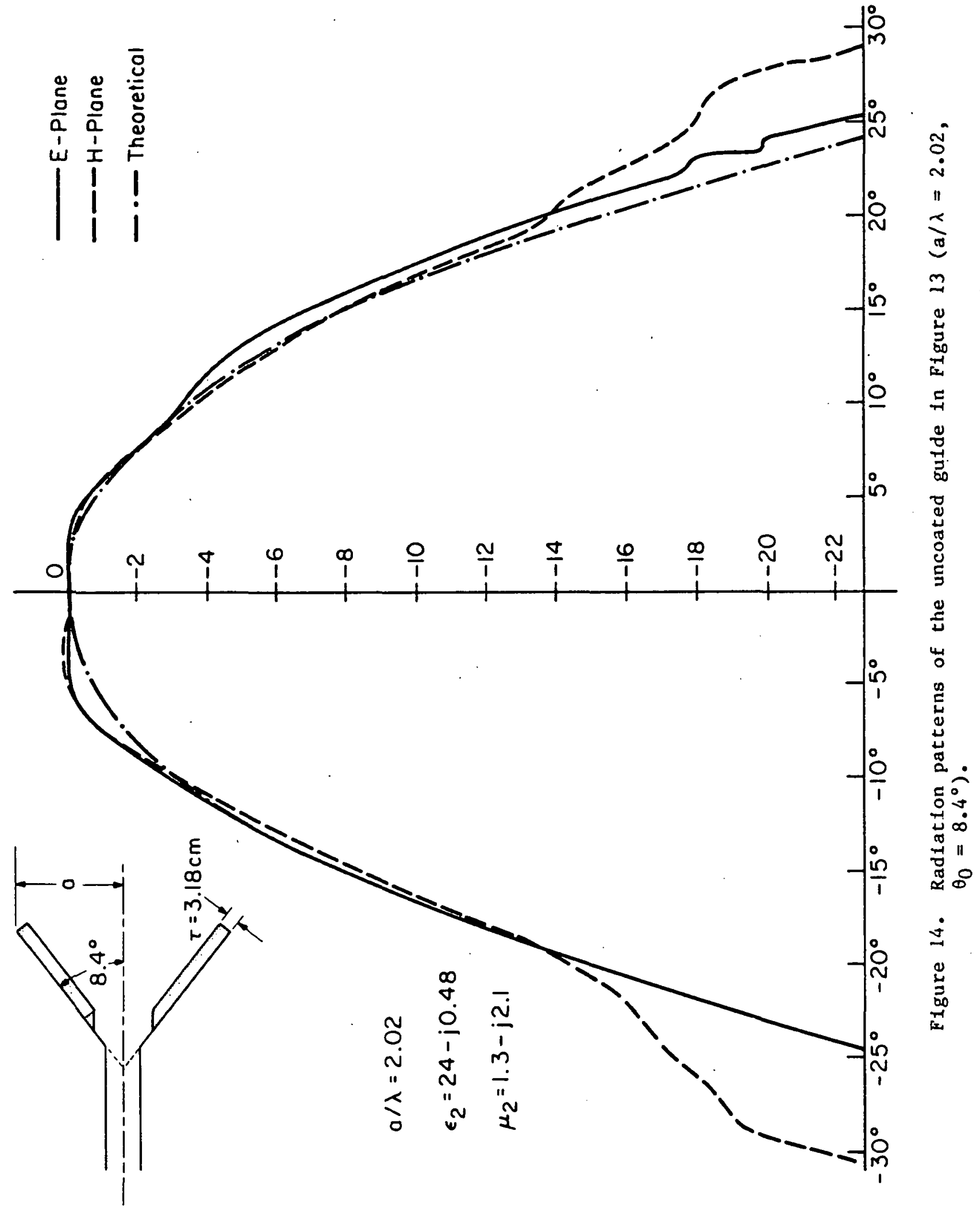




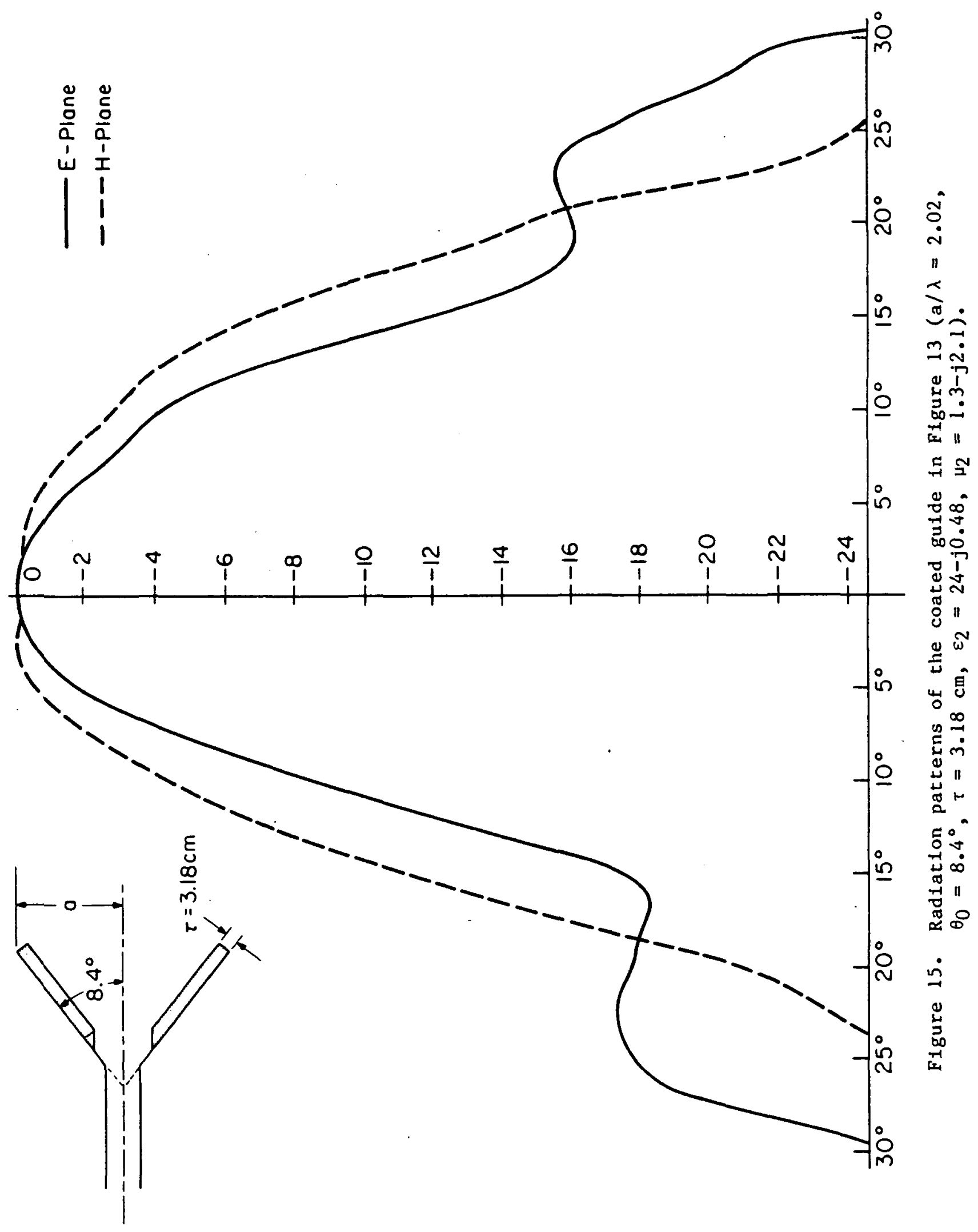




\section{v. CONCLUSION}

It has been shown that the wavegulde coated with a lossy magnetic material can support the balanced hybrid $\mathrm{HE}_{11}$ mode, which can be used to produce a circularly polarized radiation. The radius of the waveguide/horn at the opening should be larger than the free-space wavelength, and the coating material must be magnetic and very lossy. It is theoretically predicted and experimentally confirmed that the horn coated with a lossy magnetic material can be used to produce similar radiation patterns in both the $\mathrm{E}$ and $\mathrm{H}$ planes, and can be $a$ substitute for a corrugated horn to produce a $\mathrm{CP}$ radiation or to reduce the sidelobe level. 
REFERENCES

[1] M. J. Al-Hakkak and Y. T. Lo, "Circular waveguides and horns with anisotropic and corrugated boundaries," Antenna Laboratory Report No. 73-3, University of Illinois, Urbana, Illinots, 1973.

[2] P. D. Potter, "A new horn antenna with suppressed sidelobes and equal bandwidth," Microwave Journal, vol. 6, pp. 71-78, 1963.

[3] P. J. B. Clarricoats and E. E. R. C. Salema, "Antenna employing conical dielectric horns. Part 1-Propagation and radiation characteristics of dielectric cones," Proc. IEE. vol. 120, pp. 741-749, July 1973.

[4] P. J. B. Clarricoats and E. E. R. C. Salema, "Antennas employing conical dielectric horns. Part 2-The Cassegrain antenna," Proc. IEE, vol. 120, pp. 750-756, July 1973.

[5] E. Lier, "A dielectric hybrid mode antenna feed: a simple alternative to the corrugated horn," IEEE Trans. Antennas Propagat., vol. AP-34, pp. 21-29, Jan. 1986.

[6] P. J. B. Clarricoats, A. D. Olver, and S. L. Chong, "Attenuation in corrugated circular waveguide, Part 1, Theory," Proc. IEE, vol. 122, pp. $1173-1179,1975$.

[7] C. Dragone, "Reflection and mode conversion in a corrugated feed," Bell System Tech. J., vol. 56, pp. 835-867, 1977.

[8] C. Dragone, "Attenuation and radiation characteristics of the HE mode," IEEE Trans. Microwave Theory Tech., vol. MTT-28, pp. 704-710, 1980.

[9] C. S. Lee, S. L. Chuang, and S. W. Lee, "A simple version of corrugated guide: smooth-walled circular waveguide coated with lossy magnetic material," AP-S Int. Symp. Dig., vol. 1, pp. 303-306, 1985.

[10] C. S. Lee, S. W. Lee, and S. L. Chuang, "Normal modes in an overmoded circular waveguide coated with lossy material," IEEE Trans. Microwave Theory Tech., vol. MTT-34, pp. 773-785, July 1986.

[11] V. H. Rumsey, "Horn antennas with uniform power patterns around their axes," IEEE Trans. Antennas Propagat., vol. AP-14, pp. 656-658, Sept. 1966.

[12] H. C. Minnett and B. M. Thomas, "A method of synthesizing radiation patterns with axial symmetry," IEEE Trans. Antennas Propagat., vol. AP-14, pp. 654-656, Sept. 1966.

[13] E. A. J. Marcatili and R. A. Schmeltzer, "Hollow metallic and dielectric waveguides for long distance optical transmission and lasers," Bell System Tech. J., pp. 1783-1809, July 1964.

[14] H. Unger, "The optimum tapered transmission line matching section," Proc. IRE, vol. 44, pp. 539-548, April 1956. 